\title{
Boron leaching: Creating vacancy-rich Ni for enhanced hydrogen evolution
}

Chao Han ${ }^{a}$, Weijie Li, ${ }^{b}$ Jiazhao Wang, ${ }^{b}$ and Zhenguo Huang*a

a. School of Civil and Environmental Engineering, University of Technology Sydney, Sydney, NSW 2007, Australia.

b. Institute for Superconducting \& Electronic Materials, AIIM Building, Innovation Campus, University of Wollongong, Squires Way, North Wollongong, NSW 2500, Australia.

\section{AUTHOR INFORMATION}

\section{Corresponding Author}

*Zhenguo Huang, Email: zhenguo.huang@uts.edu.au. 
ABSTRACT: Creating vacancy is often highly effective in enhancing the hydrogen evolution performance of transition metal-based catalysts. Vacancy-rich Ni nanosheets has been fabricated via topochemical formation of $2 \mathrm{D} \mathrm{Ni} 2 \mathrm{~B}$ on graphene precursor followed by boron leaching. Anchored on graphene, a few atomic layered $\mathrm{Ni}_{2} \mathrm{~B}$ nanosheets are first obtained by reduction and annealing. Large number of atomic vacancies are then generated in the $\mathrm{Ni}_{2} \mathrm{~B}$ layer via leaching boron atoms. When used for hydrogen evolution reaction (HER), the vacancy-rich $\mathrm{Ni} / \mathrm{Ni}(\mathrm{OH})_{2}$ heterostructure nanosheets demonstrate remarkable performance with a low overpotential of 159 $\mathrm{mV}$ at a current density of $10 \mathrm{~mA} \cdot \mathrm{cm}^{-2}$ in alkaline solution, a dramatic improvement over $262 \mathrm{mV}$ of its precursor. This enhancement is associated with the formation of vacancies which introduce more active sites for HER along $\mathrm{Ni} / \mathrm{Ni}(\mathrm{OH})_{2}$ heterointerfaces. This work offers a facile and universal route to introduce vacancies and improve catalytic activity.

\section{TOC GRAPHICS}

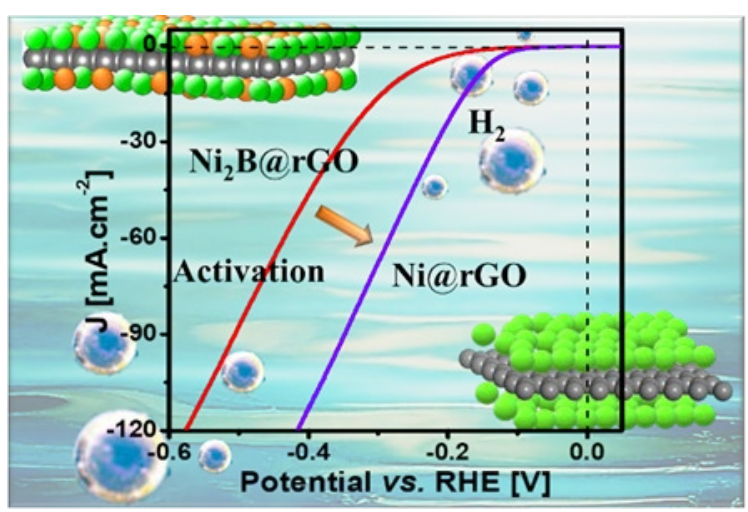

Hydrogen is a promising energy carrier since it has high energy density, is naturally abundant, and produces no pollutants when consumed. ${ }^{1-2}$ Hydrogen evolution reaction (HER) via water electrolysis has long been considered as the most sustainable way to produce hydrogen; but the 
HER process always suffers from high cost and poor stability of the noble metal based catalysts. Strong efforts have been devoted to the development of low-cost and high performance HER catalysts. ${ }^{3}$ Vacancy generation has been proved effective in improving catalytic activity since it creates more active sites and tunes the electronic structure of catalysts. ${ }^{4-6}$ Techniques such as heteroatom doping, plasma treatment, and thermal treatment, have been employed to create vacancies but they are not effective in controlling the type, location, and number of vacancies. ${ }^{7}$ Also, only a few papers attempted to understand the relationship between the formation of vacancies and catalyst stability ${ }^{8-9}$ Inspired by the efficacy of 2D structure for catalysis and the fact that boron can be effectively leached, herein a simple way to fabricate $\mathrm{Ni}$ nanosheets@graphene with atomic scaled vacancies in a controlled manner is reported. The effect of graphene on stabilizing these vacancies is also investigated. Compared with the $\mathrm{Ni}_{2} \mathrm{~B} @$ graphene precursor, the defect-rich Ni@graphene demonstrates significantly enhanced HER catalytic activity with overpotential decreased from $262 \mathrm{mV}$ to $159 \mathrm{mV}$ at a current density of $10 \mathrm{mAcm}^{-2}$. The vacancy-rich structure also exhibits excellent stability in $1 \mathrm{M} \mathrm{KOH}$ for 10 hours.

Sample preparation procedure is illustrated in Figure 1(a). $\mathrm{The}^{2+}{ }^{2+}$ ions are first adsorbed onto the negatively charged graphene oxide (GO). With the addition of $\mathrm{NaBH}_{4}$ under anaerobic condition, $\mathrm{Ni}_{2} \mathrm{~B}$ nucleation starts along the $\mathrm{rGO}$ surface and eventually grows into amorphous $\mathrm{Ni}_{2} \mathrm{~B}$ sheets according to Equation (1). ${ }^{10}$ Meanwhile, $\mathrm{GO}$ is reduced to graphene (rGO) by $\mathrm{NaBH}_{4}$. The morphology and structure of the product are studied by SEM and TEM image [Figure S1(a-c)]. Compared with bare and clean GO nanosheets [Figure S1(a)], the obtained sample appears to be fully covered with small and ultrathin nanosheets [Figure S1(b, c, and i)]. This sample adopts a structure with $\mathrm{Ni}_{2} \mathrm{~B}$ nanosheets sandwiching $\mathrm{rGO}$, which is denoted as 
NBC. Similar method was used to prepare $\mathrm{NiCoB}_{\mathrm{x}}$ nanosheets. ${ }^{11-12}$ The crystallinity of NBC sample is also poor [Figure S2(a)]. Minor amount of Ni nanocrystals [JCPDS 65-2865] are also observed [Figure S1(c-f)] which was also reported. ${ }^{13-15}$

$$
2 \mathrm{Ni}^{2+}+4 \mathrm{NaBH}_{4}+9 \mathrm{H}_{2} \mathrm{O} \rightarrow \mathrm{Ni}_{2} \mathrm{~B}+12.5 \mathrm{H}_{2} \uparrow+4 \mathrm{Na}^{+}+3 \mathrm{H}_{3} \mathrm{BO}_{3}(1)
$$

Thicknesses of the neat rGO and NBC nanosheet were estimated by EELS [details please check Part 2.1 in Supporting Information], which are found to be $3.23 \pm 0.26 \mathrm{~nm}$ and $10.14 \pm 1.99 \mathrm{~nm}$, respectively [Figure S3(a-f)]. The NBC thickness obtained from direct measurement by TEM image is $9.70 \pm 1.50 \mathrm{~nm}$, [(Figure S3(g-h)], which is close to the EELS data. Hence the thickness of $\mathrm{Ni}_{2} \mathrm{~B}$ layer on each side is between 3.2-3.5 $\mathrm{nm}$. Such thin nanostructure allows higher ratio of atoms present at the surface, which contributes to more exposed active sites and higher catalytic activity. Under the same reaction conditions but without $\mathrm{GO}, \mathrm{Ni}_{2} \mathrm{~B}$ sample (named as $\mathrm{NB}$ ) exists in agglomerates of amorphous nanoparticles, as demonstrated by SEM, TEM images in Figure $\mathrm{S} 1(\mathrm{~g}-\mathrm{h})$ and XRD patterns [Figure S2(b)]. This proves that planar rGO is conducive to the formation of amorphous $\mathrm{Ni}_{2} \mathrm{~B}$ nanosheets.

HER performance of the NB and NBC are both less satisfactory because of the amorphous nature of $\mathrm{Ni}_{2} \mathrm{~B}$; so thermal anneal was carried out to improve the crystallinity under inert atmosphere. Figure S4 presents the HER performance of NBC and NB samples annealed at different temperatures. The NBC samples exhibit better activity than NB samples annealed at the same temperature, likely benefiting from conductive graphene and the nanosheet structure. Also, with variation in annealing temperature, the NBC-200 sample (annealed at $200{ }^{\circ} \mathrm{C}$ for 2 hours) displays the best activity with minimal HER overpotential at $10 \mathrm{~mA} \cdot \mathrm{cm}^{-2}\left(\mathrm{HER} \eta_{10}\right)$ of $262 \mathrm{mV}$ 
and a Tafel slope of $134 \mathrm{mV} / \mathrm{dec}$. The HER activity varies with annealing temperatures because of factors including crystallinity, compositions, and surface areas. XRD patterns indicate the

(a)

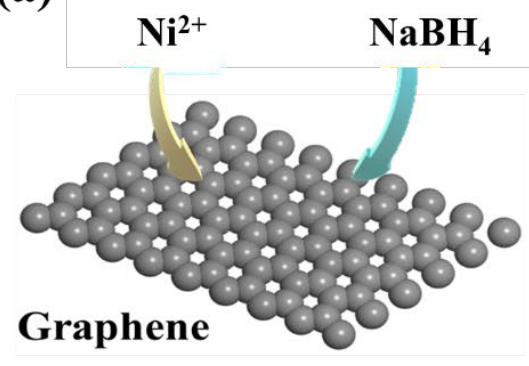

B Vacancy

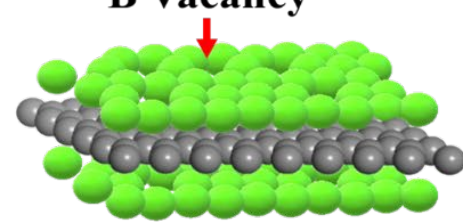

Defective Ni superlattice
Activation

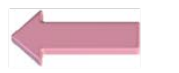

$\mathbf{N i}$

\section{Amorphous $\mathrm{Ni}_{2} \mathrm{~B}$}
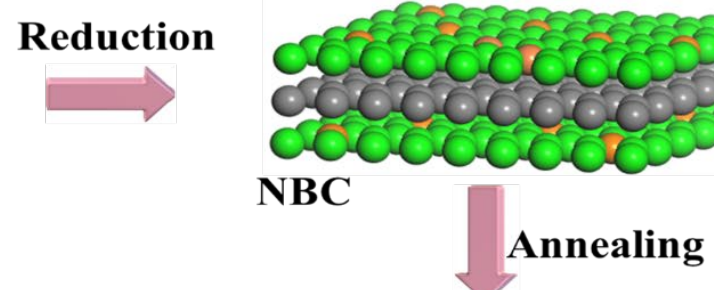

Partially ordered

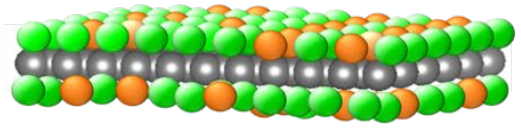

NBC-200
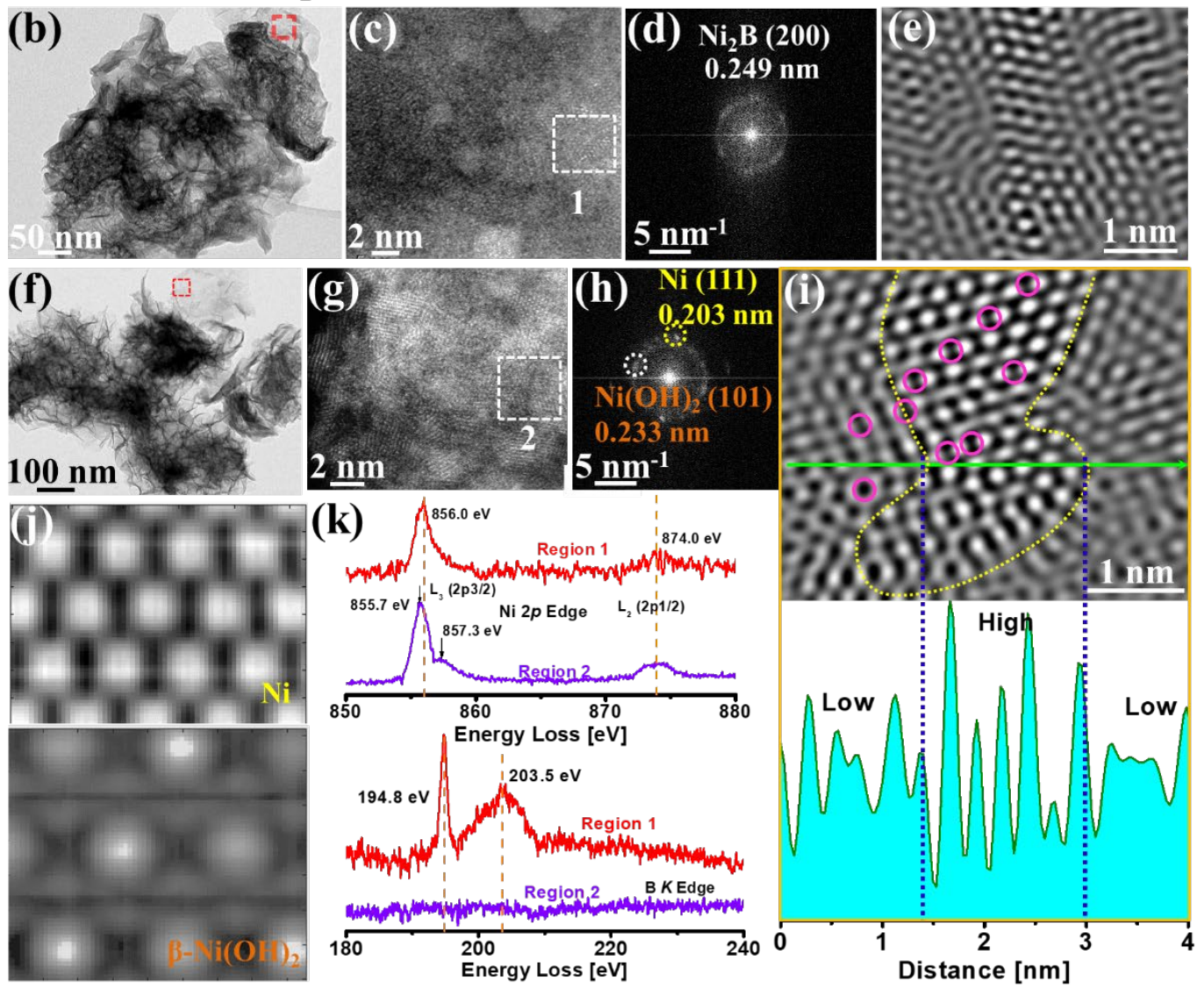
Figure 1. (a) Schematic of sample preparation. (b) Low magnification TEM image of NBC-200 sample; (c) high magnification TEM images of the red square part in (b); (d) FFT image of (c); (e) IFFT image of region 1 in (c). (f) Low magnification TEM image of ANBC-200 sample; (g) high magnification TEM image of the red square part in (f); (h) FFT image of (g); (i) IFFT image of region 2 in (g) with pink circles highlighting atomic vacancies, the yellow dashed line outlining the two areas with different brightness; brightness along the green line is shown in the below part; (j) the simulated STEM image of pure $\mathrm{Ni}$ and $\beta-\mathrm{Ni}(\mathrm{OH})_{2}$; (k) EELS of Ni $2 p$ and B $K$ edge in region 1 and 2.

As displayed in Figure 1(b), the NBC-200 becomes crumpled after annealing. Clear diffraction ring corresponding to (200) plane of $\mathrm{Ni}_{2} \mathrm{~B}$ [JCPDS 48-1222] could be observed [Figure 1(c-e)]. The better crystallinity is also evidenced by the XRD pattern of NBC-200 in Figure S2(a), in which two peaks at $36.0^{\circ}$ and $58.4^{\circ}$ appear, corresponding to (200) and (310) peaks of $\mathrm{Ni}_{2} \mathrm{~B}$ [JCPDS 48-1222], respectively. The HRTEM and inverse fast-Fourier transform (IFFT) picture of region 1 displays clear crystalline structure with various crystal orientations [Figure 1(e)]. Uniform C, Ni, and B distribution in NBC-200 could be confirmed by the EDS mapping [Figure $\mathrm{S} 1(\mathrm{i})]$. The atomic ratio of $\mathrm{Ni}$ and $\mathrm{B}$ in NBC-200 is 1.7:1 (Table S1), which is close to the atomic ratio in $\mathrm{Ni}_{2} \mathrm{~B}$.

NBC-200 sample was selected for further studies where more atomic vacancies were created via leaching boron from the $\mathrm{Ni}_{2} \mathrm{~B}$ layer, with the resulting sample being labelled as ANBC-200. The process was carried out by simply immersing the sample into air bubbled alkaline solution. $\mathrm{Ni}_{2} \mathrm{~B}$ reacts with water forming borate under this environment (Equation 2) ${ }^{19-21}$. This is proved by the high concentration of B in the alkaline solution after the activation (Table S2). The 
defective $\mathrm{Ni}$ would be oxidized into $\beta-\mathrm{Ni}(\mathrm{OH})_{2}$ in the oxygen rich alkaline solution [Equation (3)]..$^{22-24}$

$$
\begin{aligned}
& 4 \mathrm{Ni}_{2} \mathrm{~B}+12 \mathrm{OH}^{-}+3 \mathrm{O}_{2} \rightarrow 4 \mathrm{BO}_{3}^{3-}+6 \mathrm{H}_{2} \mathrm{O}+8 \mathrm{Ni} \\
& 2 \mathrm{Ni}+2 \mathrm{H}_{2} \mathrm{O}+\mathrm{O}_{2} \rightarrow 2 \mathrm{Ni}(\mathrm{OH})_{2}
\end{aligned}
$$

The ANBC-200 still adopts nanosheet morphology [Figure 1(f)], but the crystalline structure becomes more obvious [Figure 1(g-i)]. Lattice spacing of $0.233 \mathrm{~nm}$ and $0.203 \mathrm{~nm}$ are confirmed by the FFT image, which could be indexed as (101) plane of $\beta-\mathrm{Ni}(\mathrm{OH})_{2}$ [JCPDS 14-0117] and (111) plane of Ni [JCPDS 65-2865], respectively [Figure 1(h)]. As demonstrated by the IFFT image of region 2, dense atomic vacancies (marked by circles) are clearly visible [Figure 1(i)]. Two distinct areas with different brightness are also clearly identified [Figure 1(i)]. In the yellow line enclosed area, atomic vacancies are highly identifiable due to better contrast. Thermal anneal at low temperature drives certain amounts of boron into preferred positions resulting in partially ordered $\mathrm{Ni}_{2} \mathrm{~B}$, leading to non-uniform distribution of boron at atomic scale. High temperature anneal can lead to better crystalline $\mathrm{Ni}_{2} \mathrm{~B}$ but with high risk of decompose and morphological change [Figure S2(a) and Figure S5(f)]. Herein under mild conditions, the distribution of vacancies at atomic scale can be effectively controlled via removing boron in ANBC-200, as evidenced by Figure 1(i). The STEM images of $\mathrm{Ni}$ and $\beta-\mathrm{Ni}(\mathrm{OH}) 2$ were simulated using QSTEM software, which coincide with the pattern shown in Figure 1(i) [Figure 1(j)]. Hence once boron was removed from the lattice, the exposed Ni partially transformed to $\beta$ $\mathrm{Ni}(\mathrm{OH})_{2}$, which is also catalytically active towards HER. ${ }^{22,25-26}$

To further check the change in chemical composition before and after the leaching, electron energy loss spectroscopy (EELS) studies were performed. As displayed in Figure 1(k), the EELS 
spectrum of Ni shows two core-loss edges at $855.7 \mathrm{eV}$ and $873.5 \mathrm{eV}$, associated with Ni $2 p_{1 / 2}$ $\left(\mathrm{L}_{2}\right)$ and $2 p_{3 / 2}\left(\mathrm{~L}_{3}\right)$ in $\mathrm{Ni}_{2} \mathrm{~B}$, respectively. ${ }^{27}$ After leaching, the $\mathrm{L}_{3}$ edge shifts to the left slightly, while a new shoulder peak at $857.2 \mathrm{eV}$ appears, representing formation of $\mathrm{Ni}^{2+} \cdot{ }^{28-30}$ As shown in Part 2.3 of Supporting Information (SI) and Table $\mathrm{S} 3$, the $\mathrm{L}_{3} / \mathrm{L}_{2}$ ratio of region 1 and 2 increases from 2.83 to 3.67 , indicating the decreased oxidation states of $\mathrm{Ni}^{31-34}$ This coincides with the normalized white line intensity of $\mathrm{Ni}\left(\mathrm{I}_{3 \mathrm{~d}}\right)$ decrease from 0.92 to 0.67 , advocating the increased electron occupancy on $3 d$ orbit. $^{31-34}$ The core-loss edges at $194.7 \mathrm{eV}$ and a broad peak at 203.9 $\mathrm{eV}$ in the EELS spectrum of B element in region 1 could be assigned to B-O because of the surface oxidation [Figure 1(1)]. ${ }^{27}$ After being leached, the EELS signal of boron (region 2) disappears because of boron leaching. The leaching process led to the formation of vacancy-rich structure and tuned electronic states of $\mathrm{Ni}$, which would significantly affect the catalytic activity. ${ }^{35}$ The formation of hydroxide $\left[\mathrm{Ni}(\mathrm{OH})_{2}\right]$ is likely around the edges and top of the vacancies since these exposed Ni are more active. ${ }^{19-21}$

As evidenced in [Figure 2(a-c)], the HER performance of ANBC-200 is significantly better than NBC-200, with Tafel slope decreasing from 133.8 to $73.1 \mathrm{mV} / \mathrm{dec}$ and HER $\eta_{10}$ overpotential reduced from 262 to $159 \mathrm{mV}$. The enhanced HER activity is also demonstrated by the decreased charge transfer resistance $\left(\mathrm{R}_{\mathrm{ct}}\right)$, which is determined by the simulated diameter of the semicircle obtained from the electrochemical impedance spectroscopy (EIS) [Figure 2(d)]. ${ }^{36}$ The mass activity of the ANBC-200 also soars from $1422.6 \mathrm{~A} / \mathrm{g}$ to $3505.9 \mathrm{~A} / \mathrm{g}$; while the turn over frequency (TOF) at $-0.4 \mathrm{~V}$ increases from 0.047 to $0.115 \mathrm{~s}^{-1}$ (Part 2.4 in Supporting Information). The HER performance of the ANBC-200 is on par with some of the best performing borides reported, as listed in Table S4. ${ }^{37-39}$ 

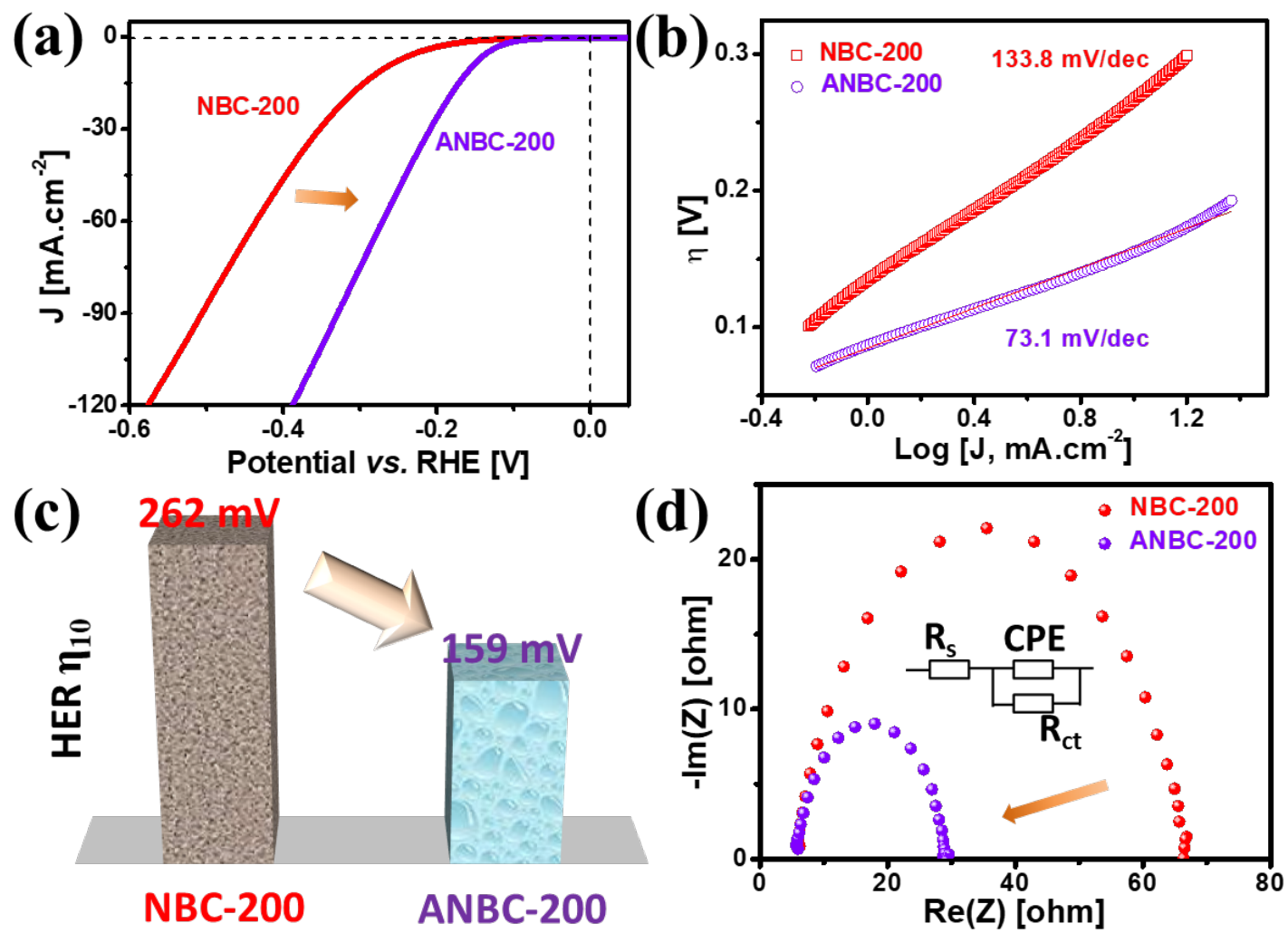

Figure 2. HER performance of NBC-200 and ANBC-200. (a) LSV curve; (b) Tafel curve; (c) HER overpotential at $10 \mathrm{~mA} \cdot \mathrm{cm}^{-2}$ current density (HER $\eta 10$ ); (d) EIS tests at $-0.3 \mathrm{~V}$ with inset showing the equivalent circuit.

The performance stability of the ANBC-200 is evaluated using chronoamperometry [Figure 3(a)]. With continuous measurement, the HER current density increases slightly from 13 to 15 $\mathrm{mA} \cdot \mathrm{cm}^{-2}$ after 10 hours test. The EIS recorded at different time intervals also verifies the stable, or even slightly improved HER activity [Figure 3(b)]. The sample maintains its layered structure after the stability test, as shown by the TEM image in Figure 3(c-d). The FFT image of the area marked by red square in Figure 3(d) shows clear diffraction spots, in which two of them correspond to the (101) plane of $\mathrm{Ni}(\mathrm{OH})_{2}$ [JCPDS 14-0117] with lattice space of $0.233 \mathrm{~nm}$ and (111) plane of Ni of $0.203 \mathrm{~nm}$, respectively [Figure 3(e-f)]. Moreover, the vacancies are still observable. The slight improved performance may come from the accrued $\mathrm{Ni}-\mathrm{Ni}(\mathrm{OH})_{2}$ 
heterostructures during the HER process in alkaline solution. ${ }^{22-23}$ Also, it seems the employment of rGO could stabilize the vacancies to some extent.
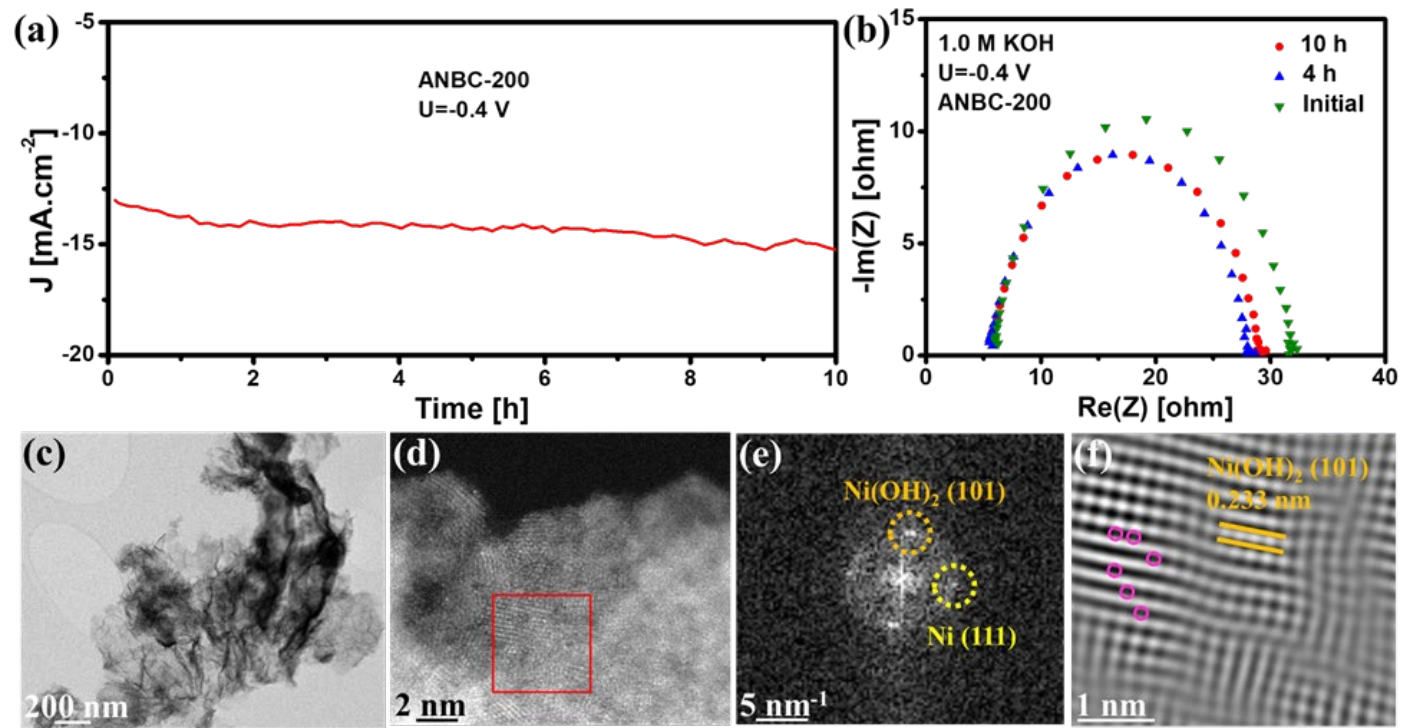

Figure 3. Stability of the ANBC-200 sample. (a) Chronoamperometry curve for 10 hours tested at $-0.4 \mathrm{~V}$ (vs. RHE). (b) EIS curves at the initial, 4 hours and 10 hours, respectively. (c) Lowmagnification and (d) high-magnification TEM image of ANBC-200 sample after 10 hours stability test. (e) Fast- Fourier transfer (FFT) image of the area marked by red square in (d). (f) IFFT image of the red square in (d); the vacancies are marked by pink circles.

This work reports a simple and effective method to prepare vacancy-rich Ni for HER via water electrolysis. After subjecting the two-dimensional $\mathrm{Ni}_{2} \mathrm{~B} @ \mathrm{rGO}$ to alkaline solution, boron can be effectively removed resulting in the $i n$-situ formation of vacancies. The formation of vacancies leads to chemically unbalanced and highly reactive $\mathrm{Ni}$ atoms, which partially transforms into $\beta$ $\mathrm{Ni}(\mathrm{OH})_{2}$ and forms a $\mathrm{Ni} / \mathrm{Ni}(\mathrm{OH})_{2}$ heterostructure. As a result, this vacancy-rich $\mathrm{Ni} / \mathrm{Ni}(\mathrm{OH})_{2} @ \mathrm{rGO}$ heterostructure displays dramatic improvement in HER performance over its 
precursor, with a low overpotential of $159 \mathrm{mV}$ (at $10 \mathrm{~mA} \cdot \mathrm{cm}^{-2}$ current density) in $1 \mathrm{M} \mathrm{KOH}$. This work sheds light on how to improve the catalytic activity of transition metal based catalyst via the formation of boron borides ( such as $\mathrm{NiB} / \mathrm{NiB}_{2}, \mathrm{NiCoB} / \mathrm{NiFeB}$ ) followed by a simple leaching process to create multi-defect rich structure. This strategy can also be implemented to produce other vacancy-rich catalysts for various chemical reactions.

\section{ASSOCIATED CONTENT}

Experimental details, characterizations and comparisons are included in the Supporting Information.

\section{Notes}

The authors declare no competing financial interest.

\section{ACKNOWLEDGMENT}

Z. Huang acknowledges support under the Australian Research Council's Future Fellowship (FT190100658). This work is partially supported by the Australian Research Council (ARC) through a Discovery project (DP180101453). W. Li is grateful for the support from a Discovery Early Career Researcher Award via DE180101478.

\section{REFERENCES}

(1) Turner, J. A. Sustainable Hydrogen Production, Science 2004, 305, 972-974.

(2) Chornet, E.; Czernik, S. Harnessing Hydrogen, Nature 2002, 418, 928-929.

(3) Zou, X.; Zhang, Y. Noble Metal-Free Hydrogen Evolution Catalysts for Water Splitting, Chem. Soc. Rev. 2015, 44, 5148-5180. 
(4) He, J.; Zou, Y.; Wang, S. Defect Engineering on Electrocatalysts for Gas-Evolving Reactions, Dalton Trans. 2019, 48, 15-20.

(5) Wang, Y.; Han, P.; Lv, X.; Zhang, L.; Zheng, G. Defect and Interface Engineering for Aqueous Electrocatalytic $\mathrm{CO}_{2}$ Reduction, Joule 2018, 2, 2551-2582.

(6) Ortiz-Medina, J.; Wang, Z.; Cruz-Silva, R.; Morelos-Gomez, A.; Wang, F.; Yao, X.; Terrones, M.; Endo, M. Defect Engineering and Surface Functionalization of Nanocarbons for MetalFree Catalysis, Adv. Mater. 2019, 31, 1805717.

(7) Jia, Y.; Jiang, K.; Wang, H.; Yao, X. The Role of Defect Sites in Nanomaterials for Electrocatalytic Energy Conversion, Chem 2019, 5, 1371-1397.

(8) Zhao, Y.; Tang, M. T.; Wu, S.; Geng, J.; Han, Z.; Chan, K.; Gao, P.; Li, H. Rational Design of Stable Sulfur Vacancies in Molybdenum Disulfide for Hydrogen Evolution, J. Catal. 2020, $382,320-328$.

(9) Choi, S.; Park, Y.; Yang, H.; Jin, H.; Tomboc, G. M.; Lee, K. Vacancy-engineered Catalysts for Water Electrolysis, CrystEngComm 2020, 22, 1500-1513.

(10) Glavee, G. N.; Klabunde, K. J.; Sorensen, C. M.; Hadjapanayis, G. C. Borohydride Reductions of Metal Ions. A New Understanding of the Chemistry Leading to Nanoscale Particles of Metals, Borides, And Metal Borates, Langmuir 1992, 8, 771-773.

(11) Sun, J.; Zhang, W.; Wang, S.; Ren, Y.; Liu, Q.; Sun, Y.; Tang, L.; Guo, J.; Zhang, X. NiCo-B Nanosheets Coupled with Reduced Graphene Oxide towards Enhanced Electrochemical Oxygen Evolution, J. Alloys Compound. 2019, 776, 511-518.

(12) Yang, M.-Q.; Dan, J.; Pennycook, S. J.; Lu, X.; Zhu, H.; Xu, Q.-H.; Fan, H. J.; Ho, G. W. Ultrathin Nickel Boron Oxide Nanosheets Assembled Vertically on Graphene: A New Hybrid 2D Material for Enhanced Photo/Electro-Catalysis, Mater. Horizons 2017, 4, 885-894. 
(13) Arzac, G. M.; Rojas, T. C.; Fernández, A. Boron Compounds as Stabilizers of a Complex Microstructure in a Co-B-based Catalyst for $\mathrm{NaBH}_{4}$ Hydrolysis, ChemCatChem 2011, 3, $1305-1313$.

(14) Geng, J.; Jefferson, D. A.; Johnson, B. F. G. The Unusual Nanostructure of Nickel-Boron Catalyst, Chem. Commun. 2007, 969-971.

(15) Xu, N.; Cao, G.; Chen, Z.; Kang, Q.; Dai, H.; Wang, P. Cobalt Nickel Boride as an Active Electrocatalyst for Water Splitting, J. Mater. Chem. A 2017, 5, 12379-12384.

(16) Li, H.; Li, H.; Deng, J.-F. The Crystallization Process of Ultrafine Ni-B Amorphous Alloy, Mater. Lett. 2001, 50, 41-46.

(17) Ozerova, A. M.; Bulavchenko, O. A.; Komova, O. V.; Netskina, O. V.; Zaikovskii, V. I.; Odegova, G. V.; Simagina, V. I. Cobalt Boride Catalysts for Hydrogen Storage Systems Based on $\mathrm{NH}_{3} \mathrm{BH}_{3}$ and $\mathrm{NaBH}_{4}$, Kinet. Catal. 2012, 53, 511-520.

(18) Singh, V.; Srinivas, V. Evolution of Ni:B ${ }_{2} \mathrm{O}_{3}$ Core-Shell Structure and Magnetic Properties on Devitrification of Amorphous NiB Particles in Air, J. Appl. Phys. 2009, 106, 053910.

(19) Licht, S.; Yu, X.; Qu, D. A Novel Alkaline Redox Couple: Chemistry of The $\mathrm{Fe}^{6+} / \mathrm{B}^{2-}$ Super-Iron Boride Battery, Chem. Commun. 2007, 2753-2755.

(20) Wang, Y. D.; Ai, X. P.; Cao, Y. L.; Yang, H. X. Exceptional Electrochemical Activities of Amorphous Fe-B and Co-B Alloy Powders Used as High Capacity Anode Materials, Electrochem. Commun. 2004, 6, 780-784.

(21) Yang, H. X.; Wang, Y. D.; Ai, X. P.; Cha , C. S. Metal Borides: Competitive High Capacity Anode Materials for Aqueous Primary Batteries, Electrochem. Solid-State Lett. 2004, 7, A212-A215. 
(22) Chhetri, M.; Sultan, S.; Rao, C. N. R. Electrocatalytic Hydrogen Evolution Reaction Activity Comparable to Platinum Exhibited by the $\mathrm{Ni} / \mathrm{Ni}(\mathrm{OH})_{2} /$ Graphite Electrode, Proc. Natl. Acad. Sci. U. S. A. 2017, 201710443.

(23) Hu, C.; Ma, Q.; Hung, S.-F.; Chen, Z.-N.; Ou, D.; Ren, B.; Chen, H. M.; Fu, G.; Zheng, N. In Situ Electrochemical Production of Ultrathin Nickel Nanosheets for Hydrogen Evolution Electrocatalysis, Chem 2017, 3, 122-133.

(24) Rao, Y.; Wang, Y.; Ning, H.; Li, P.; Wu, M. Hydrotalcite-like Ni(OH $)_{2}$ Nanosheets in Situ Grown on Nickel Foam for Overall Water Splitting, ACS Appl. Mater. Interfaces 2016, 8, $33601-33607$.

(25) Peng, L.; Liao, M.; Zheng, X.; Nie, Y.; Zhang, L.; Wang, M.; Xiang, R.; Wang, J.; Li, L.; Wei, Z. Accelerated Alkaline Hydrogen Evolution on $\mathrm{M}(\mathrm{OH})_{\mathrm{x}} / \mathrm{M}-\mathrm{MoPO}_{\mathrm{x}}(\mathrm{M}=\mathrm{Ni}, \mathrm{Co}, \mathrm{Fe}$, Mn) Electrocatalysts by Coupling Water Dissociation and Hydrogen Ad-Desorption Steps, Chem. Sci. 2020, 11, 2487-2493.

(26) Zhang, X.; Zhu, S.; Xia, L.; Si, C.; Qu, F.; Qu, F. Ni(OH) $)_{2}-\mathrm{Fe}_{2} \mathrm{P}$ Hybrid Nanoarray for Alkaline Hydrogen Evolution Reaction with Superior Activity, Chem. Commun. 2018, 54, 1201-1204.

(27) Mountjoy, G.; Corrias, A.; Gaskell, P. H. An Electron Energy Loss Spectroscopy Study of $\mathrm{Ni}_{60} \mathrm{~B}_{40}$ Alloys Prepared by Chemical Reduction and Melt Spinning, J. Non-Crystalline Solids 1995, 192-193, 616-619.

(28) Al Samarai, M.; Hahn, A. W.; Beheshti Askari, A.; Cui, Y.-T.; Yamazoe, K.; Miyawaki, J.; Harada, Y.; Rüdiger, O.; DeBeer, S. Elucidation of Structure-Activity Correlations in a Nickel Manganese Oxide Oxygen Evolution Reaction Catalyst by Operando Ni L-Edge X-ray 
Absorption Spectroscopy and 2p3d Resonant Inelastic X-ray Scattering, ACS Appl. Mater. Interfaces 2019, 11, 38595-38605.

(29) Liu, H.; Bugnet, M.; Tessaro, M. Z.; Harris, K. J.; Dunham, M. J. R.; Jiang, M.; Goward,

G. R.; Botton, G. A. Spatially Resolved Surface Valence Gradient and Structural Transformation of Lithium Transition Metal Oxides in Lithium-Ion Batteries, Phys. Chem. Chem. Phys. 2016, 18, 29064-29075.

(30) Zheng, X.; Zhang, B.; De Luna, P.; Liang, Y.; Comin, R.; Voznyy, O.; Han, L.; García de Arquer, F. P.; Liu, M.; Dinh, C. T.; Regier, T.; Dynes, J. J.; He, S.; Xin, H. L.; Peng, H.; Prendergast, D.; Du, X.; Sargent, E. H. Theory-Driven Design of High-Valence Metal Sites for Water Oxidation Confirmed Using In Situ Soft X-Ray Absorption, Nat. Chem. 2018, 10, $149-154$.

(31) Azor, A.; Ruiz-Gonzalez, M. L.; Gonell, F.; Laberty-Robert, C.; Parras, M.; Sanchez, C.; Portehault, D.; González-Calbet, J. M. Nickel-Doped Sodium Cobaltite 2D Nanomaterials: Synthesis and Electrocatalytic Properties, Chem. Mater. 2018, 30, 4986-4994.

(32) Hirayama, K.; Ii, S.; Tsurekawa, S. Transmission Electron Microscopy/Electron Energy Loss Spectroscopy Measurements and Ab Initio Calculation of Local Magnetic Moments at Nickel Grain Boundaries, Sci. Technol. Adv. Mater. 2014, 15, 015005.

(33) Pearson, D. H.; Ahn, C. C.; Fultz, B. White Lines and d-Electron Occupancies for the 3d and 4d Transition Metals, Phys. Rev. B 1993, 47, 8471-8478.

(34) Yang, W. G. The Measured Change in d-Electron of Ni in Ni-7.2 at\%Ti Alloy Studied by Electron Energy Loss Spectroscopy, Adv. Mater. Res. 2014, 887-888, 370-373. 
(35) Ai, X.; Zou, X.; Chen, H.; Su, Y.; Feng, X.; Li, Q.; Liu, Y.; Zhang, Y.; Zou, X. TransitionMetal-Boron Intermetallics with Strong Interatomic d-sp Orbital Hybridization for HighPerformance Electrocatalysis, Angew. Chem. Intl. Ed. 2020, 59, 3961-3965.

(36) Ge, Y.; Gao, S.-P.; Dong, P.; Baines, R.; Ajayan, P. M.; Ye, M.; Shen, J. Insight into the Hydrogen Evolution Reaction of Nickel Dichalcogenide Nanosheets: Activities Related to Non-Metal Ligands, Nanoscale 2017, 9, 5538-5544.

(37) Masa, J.; Weide, P.; Peeters, D.; Sinev, I.; Xia, W.; Sun, Z.; Somsen, C.; Muhler, M.; Schuhmann, W. Amorphous Cobalt Boride $\left(\mathrm{Co}_{2} \mathrm{~B}\right)$ as a Highly Efficient Nonprecious Catalyst for Electrochemical Water Splitting: Oxygen and Hydrogen Evolution, Adv. Energy Mater. 2016, 6, 1502313.

(38) Vrubel, H.; Hu, X. Molybdenum Boride and Carbide Catalyze Hydrogen Evolution in both Acidic and Basic Solutions, Angew. Chem. Intl. Ed. 2012, 51, 12703-12706.

(39) Zeng, M.; Wang, H.; Zhao, C.; Wei, J.; Qi, K.; Wang, W.; Bai, X. Nanostructured Amorphous Nickel Boride for High-Efficiency Electrocatalytic Hydrogen Evolution over a Broad pH Range, ChemCatChem 2016, 8, 708-712. 